\title{
Chromosome polymorphisms and natural selection in Leptysma argentina (Orthoptera). II. Gametic phase disequilibrium and differential adult male viability
}

\author{
PABLO C. COLOMBO* \\ Laboratorio de Genética, Departamento de Ciencias Biológicas, Facultad de Ciencias Exactas y Naturales, Universidad \\ de Buenos Aires, Ciudad Universitaria, Int. Güiraldes y Cost. Norte, (1428) Buenos Aires, Argentina
}

\begin{abstract}
Despite the wealth of information concerning inversions in natural selection (mainly in Drosophila), cases of centric fusions or supernumerary segments involved in selective processes have been less well documented. In the present study 149 males from a population of the South American grasshopper Leptysma argentina (whose generations are annual and discrete) polymorphic for a centric fusion $(F)$ and a supernumerary segment $\left(s_{1}\right)$ were sampled in October and December 1991 (the beginning and the end of the adult life span in this species) with the purpose of: (i) detecting departures from formal null models, such as Hardy-Weinberg and gametic phase equilibria; and (ii) detecting differential adult male viability among karyotypes. Both methods allow the detection of natural selection occurring in the wild. The comparison between both age classes revealed significant differences in karyotypic frequencies, which gives clear proof of ongoing selection. Gametic phase disequilibrium was not detected in young males but it was significant in aged males: favoured gametes are consistent with favoured karyotypes. Furthermore, while the young male sample does not depart significantly from Hardy-Weinberg equilibrium nor the hypothesis of homogeneity, both tests were significant in the aged male sample. Results signify that strong selective forces act in the adult stage, at least in males, while other components of natural selection remain obscure. The possible causes of selection acting on both polymorphisms are analysed and discussed.
\end{abstract}

Keywords: centric fusion, gametic disequilibrium, natural selection, supernumerary segment.

\section{Introduction}

Despite the considerable wealth of information reporting natural selection connected with inversions, mainly in species of the genus Drosophila (Brussard, 1984; Endler, 1986; Ruiz et al., 1986) there are far fewer examples of centric fusions engaged in selective processes, and most of these are indirect and tentative. With respect to supernumerary segments, the number of well-documented cases reporting selection is computable as zero; moreover, there is a general agreement that this type of supernumerary chromatin is selectively neutral (John, 1983; see Hewitt, 1979, for an opposite view), and B-chromosomes are directly

\footnotetext{
*Member of the CONICET (Consejo Nacional de Investigaciones Científicas y Técnicas, Argentina).

Present address: School of Biological Sciences, The University of Birmingham, Birmingham B15 2TT, U.K.
}

regarded as parasitical (Ostergren, 1945; Nur, 1977; Jones, 1991). However, this is a contentious field, since clear suggestions that B-chromosomes are associated with selectively advantageous effects have been reported (Holmes \& Bougourd, 1989, 1991).

In previous papers the centric fusion, supernumerary segment and B-chromosome polymorphisms of the South American grasshopper Leptysma argentina have been studied with respect to their effects on pairing and chiasma formation (Colombo, 1990, 1992a, 1993a) as well as on morphological traits (Colombo, 1989, 1992c). Also, indirect proof that natural selection is acting on them - such as the presence of a geographical pattern, directional changes over time and the correlation with environmental variables - has been reported in the first paper of this series (Colombo, 1992d). In the present work, additional and stronger evidence of natural selection acting on two chromosome polymorphisms of $L$. argentina, namely the 
centric fusion $3 / 6$ and the supernumerary $\mathrm{s}_{1}$ segment, is given, such as the finding of gametic phase disequilibrium between both polymorphisms and the evidence of differential adult male viability among karyotypes.

\section{Materials and methods}

In the present study, 149 males of an unusually dense population (YG, see Colombo, 1992d) of L. argentina were sampled in October and December 1991, coinciding with the beginning and the end of the adult life span in this species. Generations are annual and synchronised, as proven by population studies (Colombo, unpublished), so it can be assumed that all individuals in a sample are of the same age. Collections were made on 19 October 1991 (70 males) and 8 December 1991 (79 males). The YG population is sited in the Natural Park 'El Palmar' (Province of Entre Ríos, Argentina), where interaction with human activity is minimal or absent. Although population size in this species is usually small the YG population is an exception to this rule. Also, the sampling of males is less harmful than that of females and therefore does not modify substantially the genetic pool of the population.

Males were dissected in the field and testes were fixed in 3:1 ethanol: acetic acid and subsequently stored at $4^{\circ} \mathrm{C}$. Cytological preparations were made by squashing some follicles in lactoproprionic orcein, and karyotypes were determined in meiosis.

Gametic frequencies and gametic disequilibrium measure $D$ (Lewontin \& Kojima, 1960) were calculated according to the iterative 'maximum likelihood' method devised by Hill (1974). Significance of $D$ was assessed by means of

$$
Q=\frac{4 N \cdot D^{2}}{p \cdot q \cdot r \cdot s}
$$

where $p=$ frequency of fusion $3 / 6, r=$ frequency of segment $\mathrm{s}_{1}, q=1-p$ and $s=1-r . \mathrm{Q}$ is distributed as a Chi-square function with one degree of freedom (Hartl, 1989).

\section{Results}

\section{Gametic disequilibrium between $F$ and $s_{1}$}

The sample taken in October fitted to the Hardy-Weinberg $(\mathrm{H}-\mathrm{W})$ expected frequencies $\left(\chi_{(4)}^{2}=5.812, P=0.2136 \mathrm{~ns}\right)$, although a noticeable deficit of FF-BB individuals (fusion homozygotes without $\mathrm{s}_{1}$ ) and an excess of UU-Bs $\mathrm{s}_{1}$ (unfused $\mathrm{s}_{1}$ heterozygotes) was evident (Table 1a). The sample taken in
December, by contrast, departed significantly from $\mathrm{H}-\mathrm{W}$ expectations $\left(\chi_{(3)}^{2}=9.043, P=0.0287^{*}\right)$. This is due mainly to a deficit of UF-BB individuals (fusion heterozygotes without segment) - not detected in the October sample - meanwhile the defect of FF-BB observed in October evolves to a noticeable excess in December (Table 1a). The UU-Bs ${ }_{1}$ category is in excess in both samples. It seems as if the most favoured karyotypes in December were $\mathrm{FF}-\mathrm{BB}, \mathrm{UU}-\mathrm{Bs}_{1}$ and $\mathrm{UF}-\mathrm{Bs}_{1}$ (see Results, next sub-section). This failure to fit to the $\mathrm{H}-\mathrm{W}$ expectations in the second sample may be indicative of natural selection, especially when the first sample showed no significant departures from the expected frequencies.

When contingency tests in both samples were carried out in order to detect lack of homogeneity, comparable results were obtained (Table 1b). The October sample revealed homogeneity between both polymorphisms $\left(\chi_{(2)}^{2}=4.024, P=0.1337 \mathrm{~ns}\right)$. But the December sample was revealed not to be in equilibrium $\left(\chi^{2}=6.844, P=0.0326^{*}\right)$ as if selection would act differentially in each karyotype (Table 1b). This fact suggests the presence of gametic phase disequilibrium, which will be tested now.

With the aim of finding the value of the statistic $D$ (Lewontin \& Kojima, 1960), which estimates gametic phase disequilibrium, the maximum likelihood method developed by Hill (1974) was used, which calculates gametic frequencies and the exact value of $D$ from genotypic (karyotypic) ones by means of an iterative process that can be easily programmed and run by computer. The significance of $D$ can be assessed by means of the statistic $Q$ (Hartl, 1989), which is distributed as a Chi-square function with one degree of freedom. Results are shown in Table 2. No gametic disequilibrium was noticed in the October sample ( $Q=0.2188, P=0.6399 \mathrm{~ns}$ ) (Table 2a) but in December $D$ was highly significant $\left(Q=7.824, P=0.0051^{* * *}\right)$ (Table $2 \mathrm{~b}$ ). The most favoured gametes in comparison with the October sample were F, B (fusion, no segment) and $\mathrm{U}, \mathrm{s}_{1}$ (unfused, segment) - i.e. the repulsion gametes, that caused the increase (in absolute value) of $D$.

\section{Differential adult male viability}

It is known that natural selection may also be detected by comparing age classes (Endler, 1986). L. argentina, as previously stressed, has the advantage, as do most Acrididae that live in environments of marked seasonality, of having synchronized generations, i.e. all individuals at a given time are of the same age (Colombo, unpublished). Hence, comparisons between two temporally spaced samples are particularly infor- 
Table 1 Comparison of samples taken on Oct. 18 and Dec. 81991 in Yarará Guazú (YG). (a) Goodness-of-fit with Hardy-Weinberg frequencies. (b)

Contingency tables. $\mathrm{BB}=$ basic homozygotes for either polymorphism; FF,

$\mathrm{UF}=$ fusion homozygotes and heterozygotes; $\mathrm{Bs}_{1}, \mathrm{~s}_{1} \mathrm{~s}_{1}=$ segment heterozygotes and homozygotes. $(\mathrm{O}=$ observed; $\mathrm{E}=$ expected. $\mathrm{e}=$ excess; $\mathrm{d}=$ deficit $)$

(a)

\begin{tabular}{|c|c|c|c|c|c|}
\hline \multicolumn{3}{|l|}{ October } & \multicolumn{3}{|l|}{ December } \\
\hline Karyotype & $\mathrm{O}$ & $\mathrm{E}$ & Karyotype & $\mathrm{O}$ & E \\
\hline UU-BB & 26 & 24.69 & UU-BB & 23 & 22.58 \\
\hline UF-BB & 22 & 21.89 & UF-BB & 21 & $27.56 \mathrm{~d}$ \\
\hline FF-BB & 4 & $8.23 \mathrm{~d}$ & $\mathrm{FF}-\mathrm{BB}$ & 13 & $8.44 \mathrm{e}$ \\
\hline UU-Bs & 4 & 4.84 & $\mathrm{UU}-\mathrm{Bs}_{1}$ & 9 & $7.29 \mathrm{e}$ \\
\hline UF- $-\mathrm{Bs}_{1}$ & 11 & $7.29 \mathrm{e}$ & $\mathrm{UF}-\mathrm{Bs}_{1}$ & 13 & $8.90 \mathrm{e}$ \\
\hline $\mathrm{FF}-\mathrm{Bs}_{1}$ & 1 & 1.61 & $\mathrm{FF}-\mathrm{Bs}_{1}$ & 0 & $2.72 d$ \\
\hline $\mathrm{UU}-\mathrm{s}_{1} \mathrm{~s}_{1}$ & 2 & $0.91 \mathrm{e}$ & & & \\
\hline Total & 70 & 70.00 & Total & 79 & 79.00 \\
\hline
\end{tabular}

(b)

\begin{tabular}{|c|c|c|c|c|c|c|c|c|c|}
\hline \multicolumn{5}{|l|}{ October } & \multicolumn{5}{|l|}{ December } \\
\hline \multirow{2}{*}{$\begin{array}{l}\mathrm{s}_{1} \\
\text { Karyotypes }\end{array}$} & \multicolumn{3}{|c|}{ Fusion karyotypes } & \multirow[b]{2}{*}{ Total } & \multirow{2}{*}{$\begin{array}{l}\mathrm{s}_{1} \\
\text { Karyotypes }\end{array}$} & \multicolumn{3}{|c|}{ Fusion karyotypes } & \multirow[b]{2}{*}{ Total } \\
\hline & UU & UF & $\mathrm{FF}$ & & & UU & UF & $\mathrm{FF}$ & \\
\hline $\mathrm{BB}+\mathrm{s}_{1} \mathrm{~s}_{1}$ & 28 & 22 & 4 & 54 & BB & 23 & 21 & 13 & 57 \\
\hline $\mathrm{Bs}_{1}$ & 4 & 11 & 1 & 16 & $\mathrm{Bs}_{1}$ & 9 & 13 & 0 & 22 \\
\hline Total & 32 & 33 & 5 & 70 & Total & 32 & 34 & 13 & 79 \\
\hline
\end{tabular}

$\chi_{(2)}^{2}=4.024, P=0.1337$ ns. $\quad \chi_{(2)}^{2}=6.844, P=0.0326^{*}$.

Table 2 Calculated gametic frequencies and gametic disequilibrium measure $\mathrm{D}$ (Lewontin \& Kojima, 1960)

\begin{tabular}{|c|c|c|c|c|c|}
\hline \multicolumn{3}{|l|}{ October* } & \multicolumn{3}{|c|}{ December $\dagger$} \\
\hline \multirow[b]{2}{*}{ Segment } & \multicolumn{2}{|l|}{ Fusion } & \multirow[b]{2}{*}{ Segment } & \multicolumn{2}{|l|}{ Fusion } \\
\hline & $\mathrm{U}$ & $\mathrm{F}$ & & $\mathrm{U}$ & $\mathrm{F}$ \\
\hline B & 0.6029 & 0.2542 & B & 0.4810 & 0.3797 \\
\hline$s_{1}$ & 0.0899 & 0.0529 & $\mathbf{s}_{1}$ & 0.1392 & $1.19 \times 10^{-7}$ \\
\hline
\end{tabular}

${ }^{*} \mathrm{D}=0.0093, \mathrm{Q}=0.2188, P=0.6399$ ns. 31 iterations.

$\dagger \mathrm{D}=-0.0529, \mathrm{Q}=7.8241, P=0.005^{* * *} .47$ iterations. mative, and hence all significant differences in karyotype frequencies between samples may be attributed to selection.

The comparison between both 1991 samples (see Table 3, with frequencies expressed as percentages for comparison) shows that karyotypes UU-BB, UF-BB (mainly), $\mathrm{FF}-\mathrm{Bs}_{1}$ and $\mathrm{UU}-\mathrm{s}_{1} \mathrm{~s}_{1}$ decrease their frequency while $\mathrm{FF}-\mathrm{BB}$ and $\mathrm{UU}-\mathrm{Bs}_{1}$ frequencies are augmented and $\mathrm{UF}-\mathrm{Bs}_{1}$ frequency remains unchanged. In order to avoid small numbers that would render artificially high $\chi^{2}$ values, four karyotype classes were created: unfused homozygotes plus fusion heterozygotes, and fusion homozygotes, either with or without the segment (Table 3). The analysis resulted in significant differences between samples, revealing that selection - more specifically its adult viability component - acted between the onset and the end of adult male $L$. argentina life span. 
Table 3 Comparisons of karyotype frequencies in October and December 1991: ( $\mathrm{i}=$ increase, $\mathrm{d}=$ decrease). (a) Karyotype frequencies (b) Contingency $\chi^{2}$ (unfused homozygotes and fusion heterozygotes were pooled) (a)

\begin{tabular}{|c|c|c|c|}
\hline Karyotype & October & & December \\
\hline \multicolumn{4}{|l|}{ (i) Absolute values } \\
\hline $1 \mathrm{UU}-\mathrm{BB}$ & 26 & & 23 \\
\hline $2 \mathrm{UF}-\mathrm{BB}$ & 22 & & 21 \\
\hline $3 \mathrm{FF}-\mathrm{BB}$ & 4 & & 13 \\
\hline $4 \mathrm{UU}-\mathrm{Bs}_{1}$ & 4 & & 9 \\
\hline $5 \mathrm{UF}-\mathrm{Bs}_{1}$ & 11 & & 13 \\
\hline $6 \mathrm{FF}-\mathrm{Bs}_{1}$ & 1 & & 0 \\
\hline $7 \mathrm{UU}-\mathrm{s}_{1} \mathrm{~s}_{1}$ & 2 & & 0 \\
\hline Total & 70 & & 79 \\
\hline \multicolumn{4}{|l|}{ (ii) Percentages } \\
\hline $1 \mathrm{UU}-\mathrm{BB}$ & 37.1 & & $29.1 d$ \\
\hline $2 \mathrm{UF}-\mathrm{BB}$ & 31.4 & & $26.6 \mathrm{~d}$ \\
\hline $3 \mathrm{FF}-\mathrm{BB}$ & 5.7 & & $16.5 \mathrm{i}$ \\
\hline $4 \mathrm{UU}-\mathrm{Bs}_{1}$ & 5.7 & & $11.4 \mathrm{i}$ \\
\hline $5 \mathrm{UF}-\mathrm{Bs}_{1}$ & 15.7 & & 16.5 \\
\hline $6 \mathrm{FF}-\mathrm{Bs}_{1}$ & 1.4 & & $0.0 \mathrm{~d}$ \\
\hline $7 \mathrm{UU}-\mathrm{s}_{1} \mathrm{~s}_{1}$ & 2.9 & & $0.0 \mathrm{~d}$ \\
\hline Total & 100.0 & & 100.0 \\
\hline \multicolumn{4}{|l|}{ (b) } \\
\hline Karyotypic classes & October & December & Total \\
\hline $\mathrm{UU}-\mathrm{BB}+\mathrm{UF}-\mathrm{BB}$ & 48 & 44 & 92 \\
\hline FF-BB & 4 & 13 & 17 \\
\hline $\mathrm{UU}-\mathrm{Bs}_{1}+\mathrm{UF}-\mathrm{Bs}_{1}$ & 15 & 22 & 37 \\
\hline $\mathrm{FF}-\mathrm{Bs}_{1}+\mathrm{UU}-\mathrm{s}_{1} \mathrm{~s}_{1}$ & 3 & 0 & 3 \\
\hline Total & 70 & 79 & 149 \\
\hline
\end{tabular}

$\chi_{(3)}^{2}=8.751, P=0.0328^{*}$.

\section{Discussion}

According to Endler (1986) there are many methods for detecting natural selection in wild populations: the oldest and most common is the correlation of traits with environmental variables. However, more accurate and less indirect methods through which the operation of selection can be inferred are in existence, such as (from less to more direct): temporal directionality or stability in trait frequency; deviation from formal null models (such as Hardy-Weinberg and gametic phase equilibria); and the comparison between age classes (Endler, 1986; Hartl, 1989). The latter is a fairly direct method of demonstrating ongoing natural selection (Endler, 1986).
In the first paper of this series (Colombo, 1992d) we revealed the existence of a clear geographical pattern for three polymorphisms of Leptysma argentina, namely fusion $3 / 6$, segment $s_{1}$ and the B-chromosome, as well as correlations of the two former along with temperature and rain levels. Directional changes, also correlated with the same climatic variables, were also detected among and within generations.

The detection of an unusually dense population of L. argentina in a Natural Park (which prevents eventual human disturbance) allowed us to obtain samples of grasshoppers both at the beginning and the end of the adult stage within a generation. Karyotype frequencies between newly emerged and aged adults were significantly different. This allows us to conclude that male adult viability depends largely on the karyotype, some of them $\left(\mathrm{FF}-\mathrm{BB}\right.$ and $\mathrm{UU}-\mathrm{Bs}_{1}$ : fusion homozygotes without segment and segment heterozygotes without fusion) being at an advantage over the rest. It must be pointed out that these results may be caused by genes linked to the rearrangement, rather than by the karyotype itself. This may be especially true in fusion carriers, since recombination between fused and unfused chromosomes 3 and 6 in the heterozygotes is reduced due to the strict distal localization of chiasmata in the trivalent, thus allowing genetic divergence between fused and unfused 3 and 6 to occur.

Of course, this kind of study provides information only on adult male viability while other components of selection remain obscure. Methods for detecting gametic phase disequilibrium, however, imply the operation of selection before the sample is taken, assuming random mating in the wild. The method employed here (Hill, 1974) failed to find gametic disequilibrium in young males, but it was successful in aged ones, indicating again the operation of selection in this stage. The most favoured gametes in aged males were $\mathrm{F}, \mathrm{B}$ (fusion, no segment) and $\mathrm{U}, \mathrm{s}_{1}$ (segment, no fusion). This is consistent with the increased frequencies of $\mathrm{FF}-\mathrm{BB}, \mathrm{UF}-\mathrm{s}_{1}$ and $\mathrm{UU}-\mathrm{Bs}_{1}$ karyotypes in this sample and is also coherent with the departures from both Hardy-Weinberg equilibrium and the hypothesis of homogeneity observed in this sample (cf. Results, first sub-section). Hence, it can be stated beyond doubt that natural selection acted on adult males of $L$. argentina favouring some karyotypes and disfavouring others.

However, it is difficult to find out the real causes of selection. Profound and consistent effects of fusion $3 / 6$ on intra- and interchromosome chiasma distribution were detected (Colombo, 1990) due to increased chiasma interference in fusion carriers (Colombo, 1993a). This leads to a general decrease in recombination (Colombo, 1992b). Noticeable exophenotypic 
effects were also found (Colombo, 1989, 1993b), fusion carriers being significantly larger. However, it is difficult to ascertain the selective role of these effects if they happen to have any. The case of segment $s_{1}$ is even more difficult to interpret, since significant body size and chiasma effects were detected in some populations, but not in others. This lack of homogeneity is in sharp contrast to the invariable presence of this segment in all the populations sampled so far, despite the fact that these samples cover a wide geographical area. Maybe the visible effects are not 'visible' for selection, and vice versa. This study, which we believe for the first time reports selective properties of a supernumerary segment, is the first step in approaching this problem and forms the basis for continued study, e.g. obtaining of larger samples in the same and other populations, the analysis of other selection components in other developmental stages and also in females. Further study is thus required in order to obtain a more complete insight of natural selection acting on chromosome polymorphisms in Leptysma argentina.

\section{Acknowledgements}

The author is grateful to Dr María Isabel Remis for critical reading and useful comments on the manuscript and to the Dirección Nacional de Parques Naturales (National Board of Natural Parks, Argentina) for allowing collection in Natural Park 'El Palmar'. Financial support from the Consejo Nacional de Investigaciones Científicas y Técnicas (CONICET) and the Secretaria de. Ciencia y Técnica (Argentina) through grants to Drs J. H. Hunziker and C. A. Naranjo is gratefully acknowledged.

\section{References}

BRUSSARD, P. E. 1984. Geographic patterns and environmental gradients: the central-marginal model revisited. Ann. Rev. Ecol. Syst., 15, 24-64.

ColomBo, P. C. 1989. Chromosome polymorphisms affecting recombination and exophenotypic traits in Leptysma argentina (Orthoptera): a populational survey. Heredity, 62, 289-299.

соLомBo, P. c. 1990. Effects of centric fusions on chiasma frequency and position in Leptysma argentina (Acrididae: Orthoptera). II. Intra- and interchromosome effects. Caryologia, 43, 131-147.
COLOMBO, P. C. 1992a. Supernumerary segments of a bivalent of Leptysma argentina (Orthoptera): Intra- and interchromosome chiasma effects. Caryologia, 45, 283-299.

CоLомBo, P. c. 1993a. A polymorphic centric fusion enhances chiasma interference in Leptysma argentina (Orthoptera): a chiasma distribution study. Heredity, 70, 254-265.

соLомво, P. c. 1993b. Exophenotypic effects of chromosomal change: the case of Leptysma argentina (Orthoptera). In preparation.

Colombo, P. C. 1992 d. Chromosome polymorphisms and natural selection in Leptysma argentina (Orthoptera). I. Correlation with geographical, temporal and environmental variables. Submitted.

соцомво, в. с. 1992b. A new index for estimating genetic recombination from chiasma distribution data. Heredity, 69, 412-414.

ENDLER, J. A. 1986. Natural Selection in the Wild. Princeton University Press, Princeton, New Jersey.

HARTL, D. L. 1989. Principles of Population Genetics, 2nd edn. Sinauer Associates Inc., Sunderland, MA.

HEWIT, G. M. 1979. Animal Cytogenetics. Vol. 3. Insecta 1: Orthoptera. Gebrüder Bornträger, Berlin-Stuttgart.

HILL, w. G. 1974. Estimation of linkage disequilibrium in randomly mating populations. Heredity, 38, 229-239.

HOLMES, D. S. AND BOUGOURD, S. M. 1989. B-chromosome selection in Allium schoenoprasum I. Natural populations. Heredity, 63, 83-87.

HOLMES, D. S. AND BOUGOURD, S. M. 1989. B-chromosome selection in Allium schoenoprasum II. Natural populations. Heredity, 67, 117-122.

JOHN, B. 1983. The role of chromosome change in the evolution of orthopteroid insects. In: Sharma, A. K. and Sharma, A. M. (eds), Chromosomes in the Evolution of Eukaryotic Groups, Vol. I. C.R.C. Press, Boco Raton, FL, pp. $1-114$.

JONES, R. N. 1991. B-chromosome drive. The American Naturalist, 137, 430-442.

LEWONTIN, R. C. AND KOJIMA, K. 1960. The evolutionary dynamics of complex polymorphisms. Evolution, 14, 458-472.

NUR, U. 1977. Maintenance of a 'parasite' B chromosome in the grasshopper, Melanoplus femur-rubrum. Genetics, 87, 499-512.

OSTERGREN, G. 1945. Parasitie nature of extra fragment chromosomes. Botanisker Notiser, 2, 157-163.

RUIZ, A., FONTDEVILA, A., SANTOS, M., SEOANE, M. AND TORROJA, E. 1986. The evolutionary history of Drosophila buzzatii. VIII. Evidence for endocyclic selection acting on the inversion polymorphism in a natural population. Evolution, 40, 740-755. 